\title{
Pré-tratamento hidrotérmico de resíduos do milho visando à produção de etanol de segunda geração
}

Hydrothermal pretreatment of corn residues for second generation ethanol production

\author{
M. S. R. Santos-Rocha ${ }^{1 *}$; R. B. A. Souza ${ }^{1}$; G. M. Silva ${ }^{1}$; A. J. G. Cruz ${ }^{1,2}$; R. M. \\ R. G. Almeida ${ }^{3,4}$ \\ ${ }^{1}$ Programa de Pós-Graduação em Engenharia Química, Universidade Federal de São Carlos, 13565-905, São \\ Carlos - SP, Brasil \\ ${ }^{2}$ Departamento de Engenharia Química da Universidade Federal de São Carlos, 13565-905, São Carlos - SP, Brasil \\ ${ }^{3}$ Programa de Pós-Graduação em Engenharia Química, Universidade Federal de Alagoas, 57072-970, Maceió - AL, \\ Brasil \\ ${ }^{4}$ Centro de Tecnologia, Universidade Federal de Alagoas, 57072-970, Maceió - AL, Brasil \\ *santosmartha2014@gmail.com
}

(Recebido em 13 de outubro de 2016; aceito em 13 de fevereiro de 2017)

\begin{abstract}
Esse trabalho avaliou o potencial de produção de etanol de segunda geração (E2G) a partir da palha e do sabugo de milho. Os resíduos do milho foram submetidos ao pré-tratamento hidrotérmico (PTH), hidrólise enzimática e fermentação. O PTH foi realizado em reator de aço inoxidável em duas condições: $170^{\circ} \mathrm{C} / 15 \mathrm{~min}$ e $195^{\circ} \mathrm{C} / 10 \mathrm{~min}$, em agitação de $200 \mathrm{rpm}$. As frações quantificadas foram: celulose, hemicelulose, lignina, cinzas, proteína e extrativos. Após pré-tratamento hidrotérmico, a amostra de palha apresentou $70,7 \%$ de remoção de hemicelulose a $170^{\circ} \mathrm{C} / 15 \min$ e $89,7 \%$ a $195^{\circ} \mathrm{C} / 10 \mathrm{~min}$. A menor perda de celulose ocorreu na condição mais branda de temperatura $\left(170^{\circ} \mathrm{C}\right)$. Em relação ao sabugo, a remoção de hemicelulose foi de $58,7 \%$ a $170^{\circ} \mathrm{C} / 15 \mathrm{~min}$ e $67,8 \%$ a $195^{\circ} \mathrm{C} / 10 \mathrm{~min}$. A menor perda de celulose foi obtida na maior temperatura $\left(195^{\circ} \mathrm{C}\right)$. As amostras pré-tratadas foram submetidas a experimentos de hidrólise enzimática e fermentação. Obteve-se $87,5 \%$ de eficiência na fermentação para a palha prétratada a $170^{\circ} \mathrm{C}$ e 15 min e $86,9 \%$ para o sabugo pré-tratado a $195^{\circ} \mathrm{C}$ e $10 \mathrm{~min}$. Os resultados indicam que os resíduos do milho são promissores para a obtenção de etanol de segunda geração visto que cerca de 2.500,000 mil litros de etanol podem ser obtidos a partir do processamento da palha e do sabugo de milho nas regiões centro-oeste, sul e sudeste do Brasil, sem aumentar as áreas de cultivo.
\end{abstract}

Palavras-chave: biomassa lignocelulósica, pré-tratamento hidrotérmico, bioetanol.

This work evaluated the potential of second generation ethanol production from husk and corn cob. Corn residues were submitted to hydrothermal pretreatment, enzymatic hydrolysis, and fermentation. The hydrothermal pretreatment was carried out in a stainless steel reactor under two operational conditions: $170^{\circ} \mathrm{C} / 15 \mathrm{~min}$ and $195^{\circ} \mathrm{C} / 10 \mathrm{~min}$. Cellulose, hemicellulose, lignin, ash, protein, and extractives were the quantified components. After hydrothermal pretreatment, husk presented hemicellulose removal of $70.7 \%$ $\left(170^{\circ} \mathrm{C} / 15 \mathrm{~min}\right)$ and $89.7 \%\left(195^{\circ} \mathrm{C} / 10 \mathrm{~min}\right)$. The cellulose lost was lower at $170^{\circ} \mathrm{C}$. Hemicellulose removal in the corn assay was $58.7 \%\left(170^{\circ} \mathrm{C} / 15 \mathrm{~min}\right)$ and $67.8 \%\left(195^{\circ} \mathrm{C} / 10 \mathrm{~min}\right)$. The cellulose lost was lower at $195^{\circ} \mathrm{C}$. Enzymatic hydrolysis and fermentation experiments were conducted after pretreatment step. It was reached $87.5 \%$ of fermentative efficiency for the pretreated husk and $86.9 \%$ for the pretreated cob. The results suggest that corn residues are promising for second generation ethanol production since almost 2.500.000 ethanol liters can be obtained from processing husk and corn cob at midwest, south and southeast regions in Brazil, without increasing the harvest areas.

Keywords: lignocellulosic biomass, hydrothermal pretreatment, bioethanol

\section{INTRODUÇÃO}

Nos dias atuais, a crescente preocupação com o desenvolvimento sustentável vem dando ênfase à busca por fontes alternativas de energia, fazendo com que a utilização de combustíveis fósseis seja gradualmente substituída por renováveis [1]. Dentro desse contexto, os resíduos agroindustriais lignocelulósicos estão em posição de destaque, uma vez que possuem potencial considerável para a obtenção de etanol a partir de processos fermentativos [2]. A palha e o sabugo de milho, que são resíduos normalmente desperdiçados no campo, têm se mostrado 
alternativas promissoras para a produção de etanol chamado de segunda geração, que é o etanol proveniente de resíduos lignocelulósicos [3].

O milho (Zea mays) pertence à família Gramineae e é originário da América Central. Pode ser cultivado nos hemisférios norte ou sul, ao nível do mar e em regiões montanhosas, em climas úmidos e regiões secas, devido a sua grande capacidade de adaptação [4,5].

De acordo com a FAO (2016) [6] o Brasil ocupa a terceira posição entre os países produtores de milho, ficando atrás somente dos Estados Unidos e da China, sendo esse o terceiro produto agrícola mais produzido no Brasil, depois da cana-de-açúcar e da soja.

No décimo primeiro levantamento referente à safra 2015/2016, realizado pela CONAB em agosto de 2016, estimou-se que a área total semeada com milho em todas as regiões do Brasil atingiu cerca de 15.884,9 mil hectares em 2016, o que correspondeu a uma produção de $68.476,1$ mil toneladas, sendo $12.918,4$ mil hectares $(62.382,1$ mil toneladas) na região centrosul e 3.003,6 mil hectares (6.093,8 mil toneladas) na região norte-nordeste [7].

A palha e o sabugo são importantes subprodutos da indústria do milho. A palha é obtida ainda durante a colheita e na maioria dos casos não possui uma utilização definida, tornando-se um resíduo. Já o sabugo, caracterizado pela parte interna e mais densa do milho, é o resíduo gerado após o milho ser debulhado e geralmente é utilizado para ração animal [8]. Estima-se que para cada tonelada de milho processado são gerados, aproximadamente, $180 \mathrm{~kg}$ de sabugo $[9,10]$ e $700 \mathrm{~kg}$ de palha [11].

A maior dificuldade para conversão dos açúcares fermentescíveis presentes nas biomassas lignocelulósicas está relacionada com sua complexa estrutura. Três são os principais componentes presentes nas biomassas: celulose, hemicelulose e lignina [12]. A celulose, o polímero de interesse, encontra-se envolvida pela hemicelulose e lignina, o que dificulta o seu acesso. Assim, faz-se necessária a realização de uma etapa de pré-tratamento com o objetivo de desorganizar o complexo lignocelulósico e também diminuir o grau de cristalinidade da celulose [13].

O pré-tratamento tem como objetivo principal alterar a estrutura da biomassa lignocelulósica, de forma a maximizar a ação das enzimas na etapa de hidrólise, sendo os açúcares liberados destinados à fermentação [14]. Nessa etapa, diferentes pré-tratamentos têm sido desenvolvidos e propostos, incluindo-se os físicos, químicos, biológicos ou uma combinação desses [15].

Os métodos físicos têm como objetivo reduzir o tamanho de partícula (granulometria da biomassa), aumentando a superfície exposta de forma a tornar a etapa de hidrólise da biomassa mais facilmente realizável [16]. Já os métodos químicos têm o objetivo de remover a lignina e a hemicelulose, provocando pouca alteração na cadeia celulósica, que será posteriormente hidrolisada. Como a lignina está ligada às hemiceluloses, uma degradação parcial das hemiceluloses ocorre durante o processo de pré-tratamento, e dependendo das condições empregadas, a celulose pode ser degradada [17]. No pré-tratamento biológico, os fungos são os componentes que promovem a deslignificação. O objetivo do processo de biodeslignificação corresponde à solubilização da lignina por meio da ação de microrganismos, porém esses processos são muito lentos e apresentam baixos rendimentos [18].

Além de todos os fatores já citados, o pré-tratamento classifica-se como ideal se for sustentável (do ponto de vista do consumo de energia e do impacto ambiental), proporcionando posteriormente boa acessibilidade ao ataque biológico (ação das enzimas) e mínima formação de compostos inibidores [19].

Entre os diversos tipos de pré-tratamentos já estudados, o hidrotérmico, que utiliza água à temperatura e pressão elevadas, encontra-se em posição privilegiada, uma vez que é compatível com sustentabilidade e conceitos de biorrefinaria [20]. Nos últimos anos, houve grande interesse no estudo da influência da água quente sob alta pressão nos processos de conversão de biomassa. A água, que age como o solvente, deve estar em temperaturas subcríticas (entre $150 \mathrm{e}$ $230^{\circ} \mathrm{C}$ ), com o objetivo de promover a auto-hidrólise da biomassa pela liberação do grupo acetato presente na fração hemicelulósica. Esse tipo de tratamento vem sendo considerado como promissor, uma vez que a utilização apenas de água em um pré-tratamento não gera a princípio nenhum tipo de resíduo nem corrosão dos equipamentos [21,22]. 
A etapa de caracterização do material lignocelulósico é de fundamental importância, antes e depois das etapas de tratamento, para que se possam obter informações preciosas sobre os rendimentos ao longo dos processos. Sem ela é impossível avaliar se as condições utilizadas estão sendo favoráveis à produção do etanol, que é o objetivo principal [23].

É de extrema importância, portanto determinar a composição química do material para a realização de estudos de valorização de materiais lignocelulósicos. O desenvolvimento de processos para a produção de etanol a partir de biomassas envolve a otimização, de forma integrada, das etapas de pré-tratamento, hidrólise e fermentação. Para que se possa avaliar a eficiência dos diferentes processos em estudo, é essencial a determinação da composição química da biomassa, visto que a verificação das transformações ocorridas após os processos se dá principalmente por comparação dos teores das frações que compõem a biomassa [24, 25].

A Figura 1 ilustra as operações unitárias envolvidas no processo de produção do etanol de segunda geração (E2G) a partir da celulose, com seus respectivos rendimentos alcançados em cada uma das etapas do processo, tomando por base a quantidade de sabugo e palha gerados para uma tonelada de milho processado. O teor de celulose do sabugo e da palha de milho aplicado na Figura 1 foi determinado nesse trabalho e o rendimento considerado para cada uma das etapas representa valores teóricos.
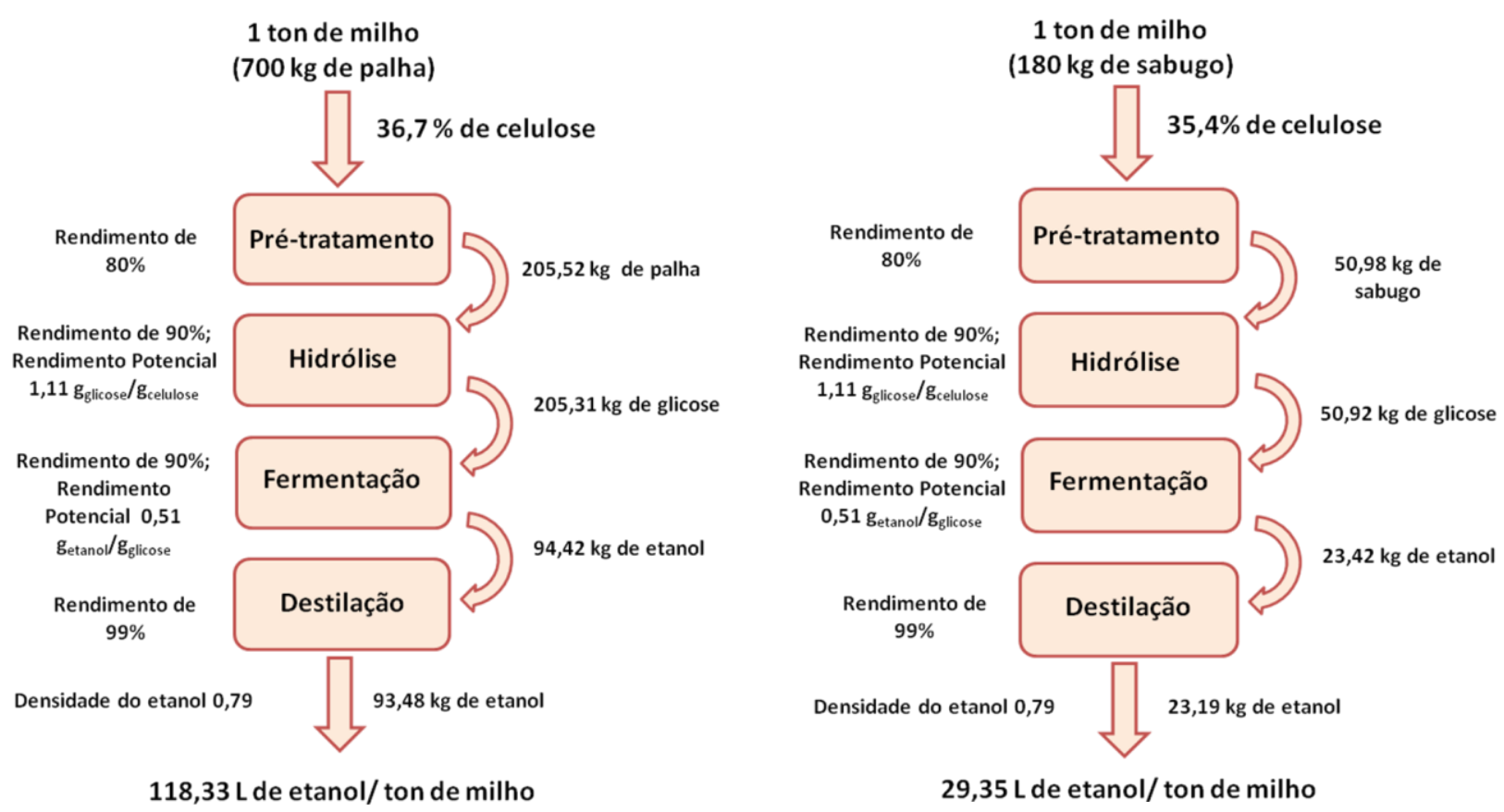

Figura 1: Potencial de obtenção de E2G a partir da celulose presente na palha e no sabugo de milho.

Nota-se pela Figura 1 que os resíduos do milho, palha e sabugo, podem contribuir para um aumento em torno de 150L de etanol por tonelada de milho cultivado, além do já obtido usualmente através da fermentação da matéria amilácea. Esse aumento é bastante significativo, visto que não necessita de aumento das áreas de cultivo e não compete com a indústria alimentícia. Baseando-se nos dados da safra de 2016 para as áreas cultivadas com milho no Brasil, indica-se aumento de 10.271,415 mil litros de etanol a partir da palha e do sabugo [7].

O aproveitamento de resíduos encontra-se diretamente associado à localização geográfica das culturas geradoras bem como de suas respectivas capacidades produtivas. Fatores essenciais, como os custos associados a transporte e armazenamento desses resíduos, podem ser minimizados levando-se em conta as regiões de maior beneficiamento potencial. Segundo dados do $\mathrm{CONAB}$, a distribuição geográfica do milho de acordo com as regiões brasileiras no ano de 2016, ocorreu com 1.963,4 mil toneladas na região norte, 4.130,4 mil toneladas na região 
nordeste, 29.558,1 mil toneladas na região centro-oeste, 9.720,9 mil toneladas na região sudeste e 23.103,1 mil toneladas de milho na região sul [7]. Nota-se, portanto, que é na região centrooeste onde há maior produção de milho, seguida pela região sul e sudeste sendo, dessa forma, as maiores geradoras de resíduos do milho, sabugo e palha. Logo, essas regiões apresentam-se como as de maior potencial para a localização de uma unidade produtiva de etanol $2 \mathrm{G}$ que tenha intuito de utilizar como fonte de biomassa os resíduos do milho.

Esse trabalho apresenta a caracterização química antes e após o pré-tratamento hidrotérmico da palha e do sabugo de milho, empregando metologia baseada em análise por cromatografia. As amostras de palha e sabugo que obtiveram os melhores resultados na etapa de pre-tratamento foram submetidas às etapas de hidrólise enzimática e fermentação. O objetivo foi avaliar a viabilidade do uso dos resíduos do milho em uma atividade de elevado valor agregado, como é o caso da produção de etanol de segunda geração.

\section{MATERIAL E MÉTODOS}

\subsection{MATERIAIS}

A palha e o sabugo de milho in natura utilizados nesse trabalho foram oriundos de espigas de milho compradas na feira livre da cidade de Maceió-AL, em abril de 2013. O extrato enzimático Accellerase ${ }^{\circledR} 1500$ (Genencor, Danisco US Inc.) foi empregando nos experimentos de hidrólise. A levedura Saccharomyces cerevisiae (levedura comercial na forma liofilizada da marca Fermix) foi utilizada na etapa de fermentação. Os demais reagentes de laboratório utilizados neste trabalho foram adquiridos em grau analítico e não sofreram qualquer tratamento antes de sua utilização.

\subsection{MÉTODOS}

\subsubsection{PREPARO DA MATÉRIA-PRIMA}

As amostras (palha e sabugo de milho) sofreram processo de sanitização após serem separadas das espigas. Esse processo consistiu em lavagem do material com solução de $\mathrm{NaClO}$ por 15 minutos. Após esse tempo, as amostras foram lavadas em água corrente. Em seguida, as amostras passaram por secagem em estufa a $45^{\circ} \mathrm{C}$. Todo material foi moído em um moinho de facas (Willye, modelo SP-30) e em seguida sua umidade determinada empregando-se uma balança com aquecimento elétrico, modelo ID50 (Marte Balanças e Aparelhos de Precisão Ltda) a $100^{\circ} \mathrm{C}$ em modo automático.

\subsubsection{PRÉ-TRATAMENTO HIDROTÉRMICO (PTH)}

O pré-tratamento hidrotérmico ocorreu em um reator de aço inoxidável com capacidade de 5L (PARR Instrument Company Moline, Illinois, EUA, modelo 4580 HP/HT). Uma amostra em base seca de palha/sabugo de milho foi misturada com água no reator utilizando-se uma carga de sólidos de $10 \%(\mathrm{~m} / \mathrm{v})$. As condições de tempo e temperatura avaliadas para ambas as biomassas foram: $170^{\circ} \mathrm{C}$ por 15 minutos de reação e $195^{\circ} \mathrm{C}$ por 10 minutos, com rotação de 200 rpm. Destaca-se que a escolha das condições empregadas para as variáveis tempo, temperatura e rotação foi baseada na literatura [26, 27, 28], em condições apontadas como promissoras para produção de etanol (alta remoção de hemicelulose com pequena degradação de celulose). Ao final da etapa de pré-tratamento, a fração sólida foi separada da fração líquida por meio de filtração em tecido. A fração sólida foi submetida à lavagem com água para a remoção da hemicelulose residual até pH neutro [29]. 


\subsubsection{RENDIMENTO APÓS PTH}

Os rendimentos mássicos da etapa de pré-tratamento hidrotérmico avaliados neste trabalho foram calculados utilizando a Equação 1.

$R=\frac{m_{\text {final }}}{m_{\text {inicial }}} \times 100$

onde: $m_{\text {inicial }}=$ massa inicial seca de material lignocelulósico $(\mathrm{g}) ; m_{\text {final }}=$ massa final seca de material lignocelulosico $(\mathrm{g}) ; R=$ rendimento mássico $(\%)$.

\subsubsection{FATOR DE SEVERIDADE ASSOCIADO AO PTH}

A Equação 2 apresenta o cálculo do fator de severidade ( $\log _{\text {ro }}$ ), um indicador de quão severo foi o pré-tratamento para a biomassa, definido por Overend et al. (1987) [30].

$$
\log _{\left(r_{0}\right)}=\log \sum_{i=1}^{n}\left[t * \exp \left(\frac{T_{i}-T_{r e f}}{14,75}\right)\right]
$$

onde: $n$ é o número de intervalos entre uma medida e outra durante a reação de pré-tratamento; $t$ é o tempo médio entre uma medida e outra; $T_{i}$ é a temperatura do pré-tratamento medida a cada

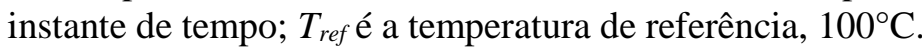

\subsubsection{CARACTERIZAÇÃO QUÍMICA DA BIOMASSA}

Para a palha e para o sabugo de milho in natura a quantidade de extrativos foi determinada empregando sistema de extração em Soxlet, usando como solvente etanol 95\% (v/v).

As amostras de palha e sabugo de milho foram caracterizadas, in natura e após prétratamento, de acordo com procedimento analítico descrito por Sluiter et al. (2008) [31], modificado por Rocha et al. (1997) [32] e validado por Gouveia et al. (2009) [24], com exceção da análise de proteínas, que foi realizada pelo método de Kjeldahl [33]. A fração líquida oriunda da etapa de caracterização foi analisada por cromatografia líquida de alta eficiência - CLAE (Cromatógrafo SHIMADZU, coluna AMINEX HPX 87H, detector UV-visível e de índice de refração - RID; fase móvel: $\mathrm{H}_{2} \mathrm{SO}_{4} 0,005$ mol.L ${ }^{-1}$; temperatura do forno de $65^{\circ} \mathrm{C}$ ). Os componentes determinados foram: lignina insolúvel na fração sólida; lignina solúvel, carboidratos, ácidos orgânicos, furfural e hidroximetilfurfural na fração líquida; cinzas.

\subsubsection{HIDRÓLISE ENZIMÁTICA}

Os experimentos de hidrólise enzimática foram realizados utilizando o extrato enzimático Accellerase ${ }^{\circledR} 1500$. Avaliaram-se apenas as biomassas pré-tratadas que resultaram em menor perda de celulose. Os ensaios ocorreram com carga de sólidos de $10 \%(\mathrm{~m} / \mathrm{v})$, meio reacional de $100 \mathrm{~mL}$, composto por material lignocelulósico pré-tratado (massa em base seca), extrato enzimático (20 FPU/ g biomassa seca) e tampão citrato, $\mathrm{pH}$ 4,8 (50 mM). As hidrólises enzimáticas foram realizadas em frascos de Erlenmeyer de $250 \mathrm{~mL}$ em Shaker $\left(50^{\circ} \mathrm{C}\right.$ e $\left.150 \mathrm{rpm}\right)$ por 72 horas. Após a hidrólise enzimática, o teor de açúcares redutores totais (ART) foi determinado por meio do método espectrofotométrico (espectrofotômetro SP 2000 UV - BEL PHOTONICS), proposto por Miller (1959) [34], que utiliza a solução de ácido 3,5dinitrosalicílico (DNS) e leitura no comprimento de onda de $540 \mathrm{~nm}$. 


\subsubsection{FERMENTAÇÃO DO HIDROLISADO}

O microrganismo utilizado para a fermentação foi a levedura Saccharomyces cerevisiae comercial na forma liofilizada. A fração líquida, contendo a glicose resultante da hidrólise enzimática dos materiais lignocelulósicos, foi utilizada como mosto.

Para o preparo do inóculo, foi utilizado o meio de cultura YPD (Yeast Peptone Dextrose). Em frascos de Erlenmeyer de $250 \mathrm{~mL}$ foram adicionados: $30 \mathrm{~mL}$ do hidrolisado, 0,6 g de peptona bacteriológica e $0,3 \mathrm{~g}$ de extrato de levedura. $\mathrm{O}$ meio foi esterilizado à $121^{\circ} \mathrm{C}$ por 15 min. Em seguida, foi adicionada $6,7 \mathrm{~mL}$ da solução de sulfato de magnésio e fosfato de amônio e por último, $0,3 \mathrm{~g}$ do fermento.

A fermentação ocorreu em Shaker $\left(30^{\circ} \mathrm{C}\right.$ e $\left.200 \mathrm{rpm}\right)$ por 24 horas. Após essa etapa, os açúcares redutores totais (ART), o teor alcoólico e a eficiência fermentativa foram determinados. O teor alcoólico foi determinado por destilação, utilizando-se o método espectrofotométrico empregando solução de dicromato de potássio [35]. A eficiência da fermentação $\left(E_{f}\right)$ foi determinada pela relação entre o rendimento real da fermentação e $o$ rendimento teórico de 0,511 [36,37].

De forma simplificada, a Figura 2 apresenta todas as etapas envolvidas na produção de etanol de segunda geração realizadas nesse trabalho.

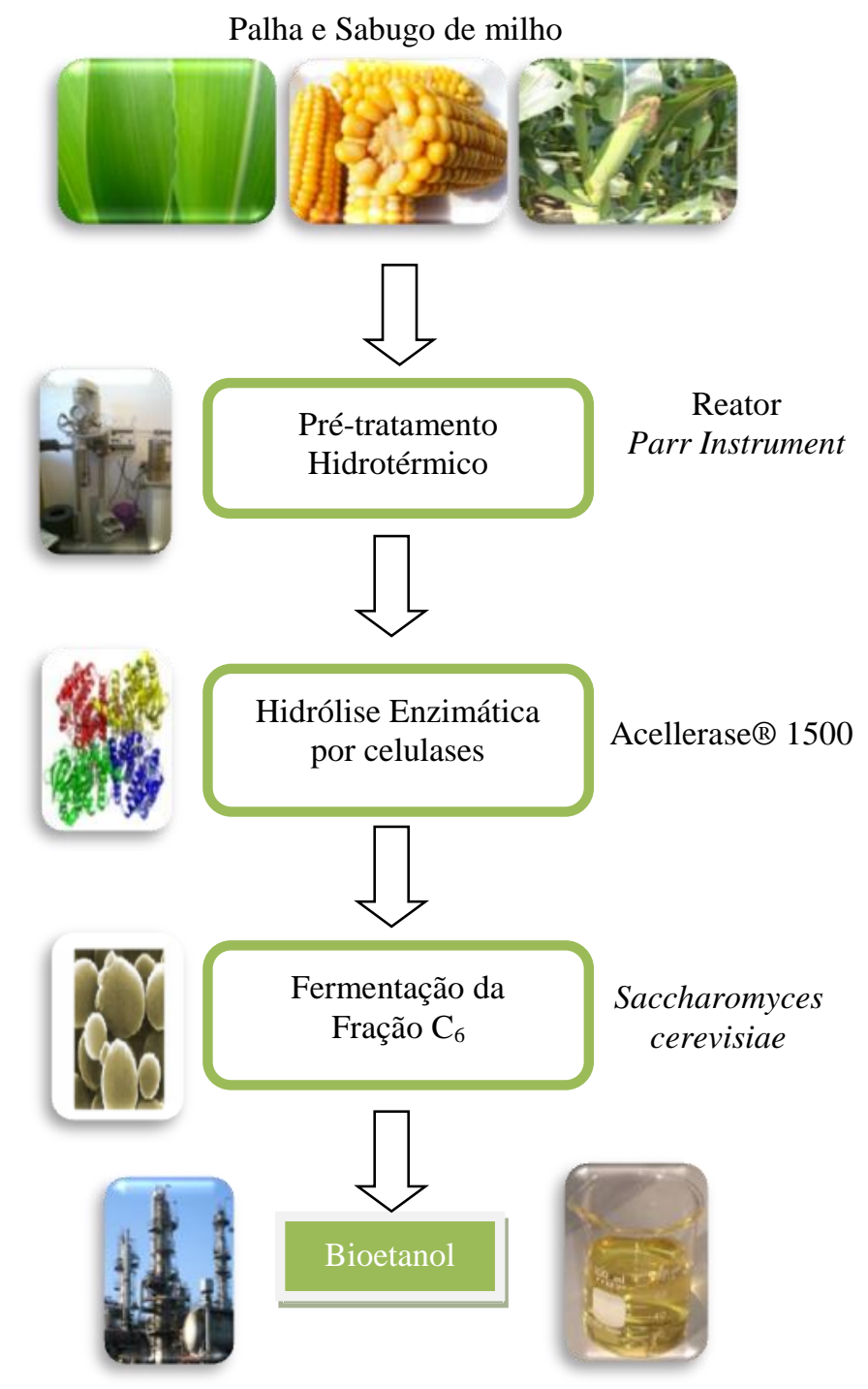

Figura 2: Etapas realizadas para obtenção do E2G. 


\section{RESULTADOS E DISCUSSÃO}

Os resultados da caracterização da palha e do sabugo de milho in natura e após a etapa de pré-tratamento hidrotérmico estão apresentados nas Tabelas 1 e 2.

Tabela 1: Composição química das amostras de palha de milho in natura e após pré-tratamento hidrotérmico

\begin{tabular}{cccc}
\hline Componentes & Palha In natura & $\begin{array}{c}\text { Palha tratada a } \\
\mathbf{1 7 0}^{\circ} \mathbf{C} \text { e 15 min }\end{array}$ & $\begin{array}{c}\text { Palha tratada a } \\
\mathbf{1 9 5}^{\circ} \mathbf{C} \text { e 10 min }\end{array}$ \\
\hline Celulose (\%) & $36,7 \pm 0,2$ & $57,6 \pm 0,3$ & $49,4 \pm 0,1$ \\
Hemicelulose (\%) & $34,2 \pm 0,1$ & $21,0 \pm 0,3$ & $8,4 \pm 0,2$ \\
Lignina total (\%) & $14,0 \pm 0,1$ & $17,8 \pm 0,1$ & $20,6 \pm 0,2$ \\
Cinzas (\%) & $2,34 \pm 0,3$ & $0,9 \pm 0,6$ & $0,7 \pm 0,3$ \\
Extrativos (\%) & $11,6 \pm 0,5$ & & \\
Proteína (\%) & $4,9 \pm 0,0$ & $0,9 \pm 0,2$ & $0,9 \pm 0,1$ \\
Rendimento mássico (\%) & - & 47,7 & 42,0 \\
Fator de Severidade & - & 3,5 & 4,2 \\
\hline
\end{tabular}

Tabela 2: Composição química das amostras de sabugo de milho in natura e após pré-tratamento hidrotérmico

\begin{tabular}{cccc}
\hline Componentes & Sabugo In natura & $\begin{array}{c}\text { Sabugo tratado a } \\
\mathbf{1 7 0}^{\circ} \mathbf{C ~ e ~ 1 5 ~ m i n ~}\end{array}$ & $\begin{array}{c}\text { Sabugo tratado a } \\
\mathbf{1 9 5}^{\circ} \mathbf{C ~ e ~ 1 0 ~} \text { min }\end{array}$ \\
\hline Celulose (\%) & $35,4 \pm 0,2$ & $40,5 \pm 0,1$ & $54,0 \pm 0,4$ \\
Hemicelulose (\%) & $26,9 \pm 0,3$ & $22,1 \pm 0,2$ & $20,9 \pm 0,1$ \\
Lignina total (\%) & $18,0 \pm 0,2$ & $21,0 \pm 0,2$ & $30,9 \pm 0,1$ \\
Cinzas (\%) & $2,4 \pm 0,1$ & $0,5 \pm 0,3$ & $0,7 \pm 0,3$ \\
Extrativos (\%) & $18,3 \pm 0,3$ & $\overline{\%}$ & $\overline{1,8 \pm 0}, 1$ \\
Proteína (\%) & $6,5 \pm 0,3$ & $1,8 \pm 0,2$ & 41,5 \\
Rendimento mássico (\%) & - & 50,4 & 4,2 \\
Fator de Severidade & - & 3,4 & \\
\hline
\end{tabular}

Por análise dos dados apresentados nas Tabelas 1 e 2, nota-se que o rendimento mássico associado à etapa de pré-tratamento hidrotérmico de ambas as biomassas diminuiu com o aumento da temperatura, resultado contrário ao fator de severidade (FS), que aumentou à medida que a temperatura se elevou. Esse comportamento sugere que a variável temperatura apresentou maior influência sobre a degradação da biomassa submetida ao pré-tratamento hidrotérmico que a variável tempo de reação, para as condições empregadas nesse estudo [38]. O FS é um indicador do quão rigoroso é o efeito do pré-tratamento para a biomassa. No prétratamento hidrotérmico a presença dos íons hidrônios, responsáveis por hidrolisar a biomassa, promoverá baixa solubilização na condição mais branda de temperatura, efeito identificado nesse trabalho [39].

A literatura reporta rendimentos mássicos que variam entre 47 e $55 \%$, após pré-tratamento hidrotérmico da palha de cana-de-açúcar. Esses tratamentos ocorreram por tempos de 10 ou 15 minutos e temperaturas entre $180 \mathrm{e} 195^{\circ} \mathrm{C}$ [40]. Kim et al. (2013) [41] relataram valores de fator de severidade entre 3,0 e 4,4 ao realizar o pré-tratamento hidrotérmico entre 180 e $200^{\circ} \mathrm{C}$ com tempo de reação entre 15 e 30 minutos.

A Figura 3 representa os perfis de aquecimento e resfriamento associados ao tratamento hidrotérmico da palha e do sabugo de milho, para as duas condições de PTH avaliadas. 

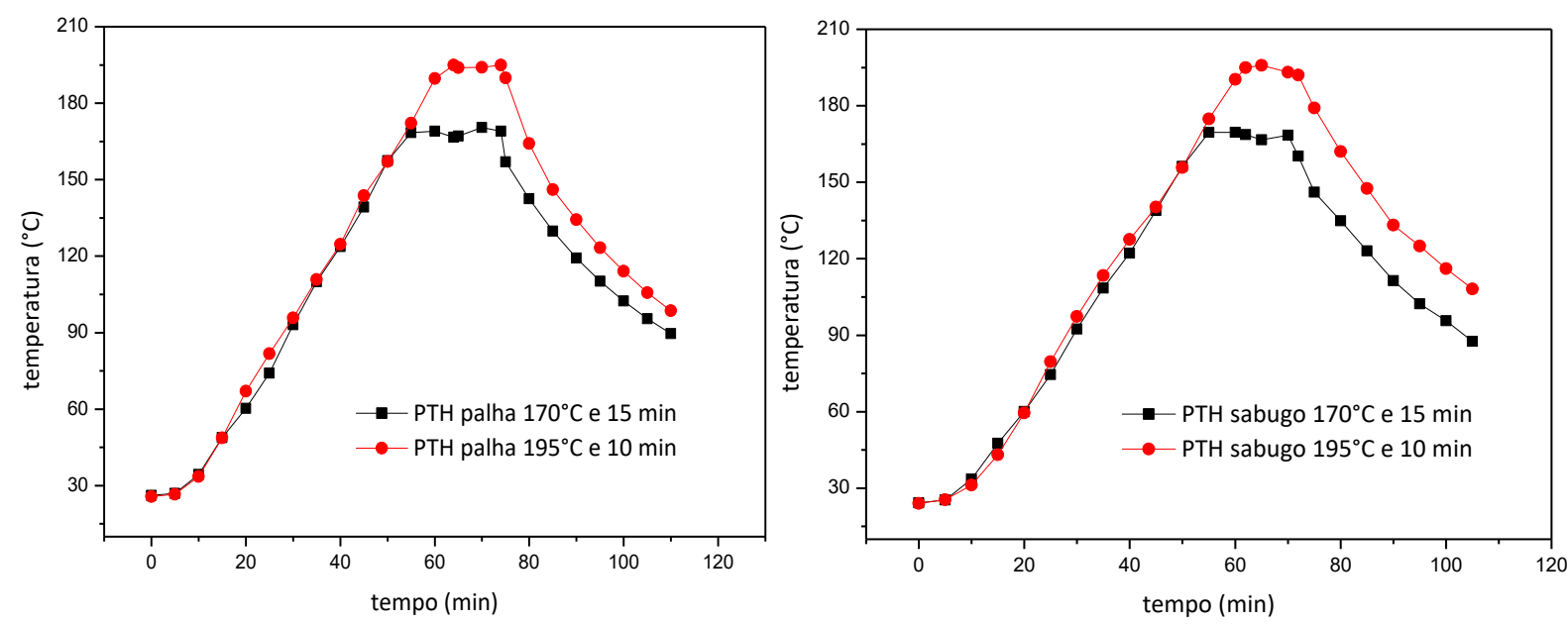

Figura 3: Perfil da temperatura durante a etapa de pré-tratamento hidrotérmico da palha e do sabugo de milho.

Nota-se pela Figura 3 que de forma geral a mesma condição de pré-tratamento apresentou perfil semelhante para a palha e para o sabugo de milho durante as etapas de aquecimento e resfriamento [42].

As Tabelas 3 e 4 apresentam os componentes principais da biomassa lignocelulósica com seus valores corrigidos pelo rendimento em massa seca obtido em cada um dos PTH's.

Tabela 3: Teor de celulose, hemicelulose e lignina com valores corrigidos pelo rendimento mássico do PTH (Palha)

\begin{tabular}{|c|c|c|c|}
\hline Componentes (\%) & Palha In Natura & $\begin{array}{l}\text { Palha tratada a } \\
170^{\circ} \mathrm{C} \text { e } 15 \mathrm{~min}^{*}\end{array}$ & $\begin{array}{l}\text { Palha tratada a } \\
195^{\circ} \mathrm{Ce} 10 \mathrm{~min}^{*}\end{array}$ \\
\hline Celulose & $36,7 \pm 0,2$ & 27,5 & 20,8 \\
\hline Hemicelulose & $34,2 \pm 0,1$ & 10,0 & 3,5 \\
\hline Lignina total & $14,0 \pm 0,1$ & 8,5 & 8,7 \\
\hline Rendimento mássico & - & 47,7 & 42,0 \\
\hline
\end{tabular}

* valores corrigidos levando-se em conta o rendimento mássico da etapa do PTH.

Analisando-se as Tabelas 3 e 4, verifica-se que houve, após pré-tratamento hidrotérmico da palha e do sabugo de milho, redução nas quantidades dos três componentes principais (celulose, hemicelulose e lignina total) em relação à quantidade inicial presente na biomassa in natura. Segundo Boussarsar et al. (2009) [43], a eficiente solubilização da fração hemicelulósica de biomassas é um efeito já esperado quando se emprega um pré-tratamento hidrotérmico, porém espera-se que esse tipo de pré-tratamento seja suave sobre a fração celulósica, resultando apenas em pequenas perdas dessa fração $[44,45]$.

Tabela 4: Teor de celulose, hemicelulose e lignina com valores corrigidos pelo rendimento mássico do PTH (Sabugo)

\begin{tabular}{|c|c|c|c|}
\hline Componentes (\%) & Sabugo In Natura & $\begin{array}{l}\text { Sabugo tratado a } \\
170^{\circ} \mathrm{C} \text { e } 15 \mathrm{~min} *\end{array}$ & $\begin{array}{l}\text { Sabugo tratado a } \\
195^{\circ} \mathrm{C} \text { e } 10 \text { min * }\end{array}$ \\
\hline Celulose & $35,4 \pm 0,2$ & 20,4 & 22,4 \\
\hline Hemicelulose & $26,9 \pm 0,3$ & 11,1 & 8,7 \\
\hline Lignina total & $18,0 \pm 0,2$ & 10,6 & 12,9 \\
\hline Rendimento mássico & & 50,4 & 41,5 \\
\hline
\end{tabular}

* valores corrigidos levando-se em conta o rendimento em massa seca do PTH. 
A Figura 4 apresenta os percentuais de remoção para as três frações principais da palha e do sabugo de milho após pré-tratamento hidrotérmico.

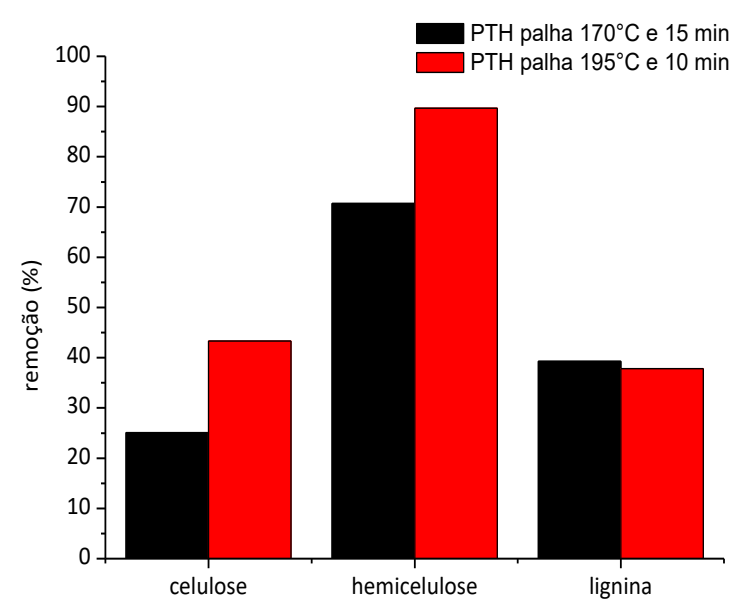

(a)

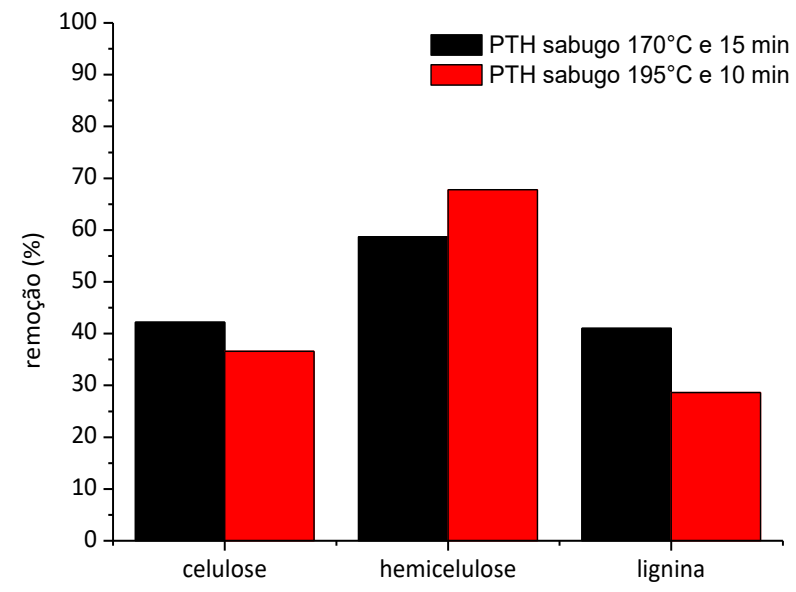

(b)

Figura 4. Remoção dos principais componentes após PTH da palha (4a) e do sabugo (4b).

A Figura 4a mostra que a condição de $170^{\circ} \mathrm{C}$ e 15 min (representada em preto), apresentou uma perda de $25,1 \%$ de celulose; $70,7 \%$ da hemicelulose e $39,3 \%$ de lignina foram removidas. Com esses resultados, observa-se que a remoção da fração de hemicelulose foi bastante satisfatória com pequena perda de celulose. Já para a condição de $195^{\circ} \mathrm{C}$ e $10 \mathrm{~min}(\mathrm{em}$ vermelho), houve remoção de $89,7 \%$ de hemicelulose e de $37,8 \%$ de lignina, com maior perda de celulose, $43,3 \%$. Nesse caso, a perda de celulose foi mais evidente, o que pode ser justificado pela degradação de açúcares em condições mais severas de pré-tratamento [46]. A redução na fração de hemicelulose foi maior e para o teor de lignina, não houve diferença significativa entre as duas condições testadas.

A palha de milho apresentou-se melhor resultado na condição de $170^{\circ} \mathrm{C}$ e 15 minutos, visto que houve menor degradação da fração celulósica sendo, portanto, essa a condição escolhida para seguir às etapas de hidrólise e fermentação. O ideal é que não haja degradação da celulose, porém, como a lignina está ligada às hemiceluloses, uma degradação parcial das hemiceluloses ocorre durante o processo de pré-tratamento, e dependendo das condições empregadas, a celulose pode também ser degradada [8].

Por análise da Figura 4b, o pré-tratamento do sabugo de milho, nas duas condições testadas, semelhante a palha, também promoveu redução no teor dos três componentes principais. $\mathrm{Na}$ condição mais branda de temperatura, $170^{\circ} \mathrm{C}$ e $15 \mathrm{~min}$ (representada em preto), a perda de celulose foi de 42,2\%, com remoção de 58,7\% de hemicelulose e de $41,0 \%$ de lignina. Observase que houve uma maior remoção de celulose frente à remoção da hemicelulose, quando comparado com o resultado obtido para a palha de milho. Já para a condição de maior temperatura, $195^{\circ} \mathrm{C}$ por $10 \mathrm{~min}$ (em vermelho), a remoção de celulose foi de $36,6 \%$ e a remoção de hemicelulose e lignina foi de $67,8 \%$ e $28,6 \%$, respectivamente. Aqui, observa-se que a remoção da hemicelulose foi satisfatória frente à de celulose. Para o caso da lignina, a maior remoção foi na condição mais branda de temperatura.

O sabugo de milho mostrou melhores resultados na condição de $195^{\circ} \mathrm{C}$ por $10 \mathrm{~min}$, pois houve menor perda de material celulósico e maior remoção de hemicelulose, sendo essa a condição escolhida para a realização da hidrólise enzimática e fermentação.

Os resultados obtidos nas etapas de hidrólise enzimática e fermentação estão apresentados na Tabela 5 . 
Tabela 5: Resultados obtidos após as etapas de hidrólise enzimática e fermentação

\begin{tabular}{ccccc}
\hline Condições & $\begin{array}{c}\text { ART * no } \\
\text { hidrolisado } \\
(\mathbf{g} / \mathbf{L})\end{array}$ & $\begin{array}{c}\text { Conversão } \\
\text { enzimática } \\
(\boldsymbol{\%})\end{array}$ & $\begin{array}{c}\text { Eficiência } \\
\text { fermentativa } \\
(\boldsymbol{\%})\end{array}$ & $\begin{array}{c}\text { Bioetanol } \\
(\mathbf{g} / \mathbf{L})\end{array}$ \\
\hline Palha à $170^{\circ} \mathbf{C} / \mathbf{1 5}$ min & $7,4 \pm 0,5$ & 42,1 & 87,5 & $3,3 \pm 0,0$ \\
Sabugo à ${\mathbf{~} 55^{\circ} \mathbf{C} / 10 \text { min }}^{*}$ & $12,4 \pm 1,6$ & 47,7 & 86,9 & $5,5 \pm 1,1$ \\
\hline
\end{tabular}

*ART: açúcares redutores totais

Analisando-se os resultados de hidrólise e fermentação apresentados na Tabela 5, observa-se que foram obtidos $5,5 \mathrm{~g} / \mathrm{L}$ de etanol a partir do sabugo de milho e $3,3 \mathrm{~g} / \mathrm{L}$ de etanol a partir da palha.

Em seus estudos, Silva (2011) [17] reporta concentrações de etanol que variaram de 3,8 a 5,7 $\mathrm{g} / \mathrm{L}$ ao se utilizar pré-tratamento alcalino com solução de $\mathrm{NH}_{4} \mathrm{OH}$ (de 4 a $15 \%$ ) empregando bagaço de cana-de-açúcar. Wolf (2011) [47] utilizou bagaço de cana pré-tratado com solvente orgânico (organossolve a $150^{\circ} \mathrm{C}$ por 30 min e etanol de 30 a $70 \%$ v/v) e alcançou na etapa de fermentação concentrações de etanol na faixa de 4,3 e 5,2 g/L.

A etapa de hidrólise apresentou baixa conversão (inferior a 50\%). O complexo enzimático Accellerase ${ }^{\circledR} 1500$ apresenta melhor estabilidade operacional em uma faixa de temperatura entre 50 e $65^{\circ} \mathrm{C}$ [48]. Visto que os ensaios de hidrólise ocorreram na condição do limite inferior da faixa de temperatura ótima, esse pode ser um indicativo de que melhores resultados poderiam ser obtidos ao se realizar ensaios de hidrólise em temperaturas maiores. Outro fator que corrobora para a baixa conversão enzimática é a perda da fração celulósica após tratamento hidrotérmico, deixando assim menos celulose disponível para posterior sacarificação.

É possível ainda realizar uma análise do volume de etanol de segunda geração potencialmente obtido (semelhantemente ao que foi estabelecido na Figura 1), de acordo com as condições avalidadas nesse trabalho (rendimento experimentalmente atingido nas etapas de prétratamento, hidrólise enzimática e fermentação) e considerando os dados de produção de milho no Brasil referentes à safra de 2016. Dessa forma, estima-se obter 2.739,044 mil litros de etanol a partir da palha e do sabugo de milho cultivados em todas as regiões brasileiras. Levando-se em conta apenas as regiões mais promissoras (centro-oeste, sul e sudeste), por apresentarem maior potencial gerador de sabugo e palha, calcula-se um potencial de produção de 2.495,284 mil litros de etanol $2 \mathrm{G}$ produzidos a partir dos resíduos do milho.

A utilização desses resíduos mostra-se, portanto bastante promissora visto que resulta em um aumento significativo na produção de etanol do país, sem necessidade de expansão das áreas de cultivo.

\section{CONCLUSÃO}

A caracterização da palha e do sabugo de milho mostrou que essas biomassas são promissoras, visto que possuem teores consideráveis de material fermentescível e que a etapa do pré-tratamento promoveu significativa remoção de hemicelulose e lignina, compostos indesejáveis quando se realiza a etapa de fermentação empregando a levedura Saccharomyces cerevisiae. O ideal é que se obtenha com o pré-tratamento um efeito suave sobre a fração celulósica aliado a uma elevada solubilização de hemicelulose e lignina. Os ensaios apresentaram perda considerável de celulose, porém boa remoção de hemicelulose e lignina, chegando ao final do processo a eficiências de fermentação em torno de $87 \%$.

Os resultados obtidos para a hidrólise enzimática e fermentação estiveram dentro do esperado, porém esse estudo pode ser aperfeiçoado, utilizando-se, por exemplo, uma faixa de condições experimentais para essas duas etapas, podendo-se assim avaliar a mais promissora. A temperatura de hidrólise é um fator que pode ser otimizado, dentro das condições de estabilidade operacional indicadas pelo fabricante.

De acordo com os dados da safra 2016, estima-se, tomando por base os resultados de prétratamento, hidrólise e fermentação obtidos nesse trabalho, uma produção de 2.495,284 mil litros de etanol de segunda geração a partir dos resíduos do milho cultivado nas regiões centrooeste, sul e sudeste. Apesar de ainda não ser uma total realidade em nosso país, o uso de 
resíduos agroindustriais lignocelulósicos para produção de energia mostra-se bastante atrativo, uma vez que potencializará a solução de problemas ambientais associados a desperdício e poluição. Além do mais, poderá diversificar a matriz energética brasileira sem que haja competição com a indústria de alimentos ou expansão das áreas agricultáveis.

\section{AGRADECIMENTOS}

Os autores agradecem a CAPES - Coordenação de Aperfeiçoamento de Pessoal de nível Superior e ao projeto "Casadinho" / PROCAD, CNPq / CAPES (Proc. no 552595/2011-0), uma cooperação entre a UFSCar, UFAL e UFRJ, pelo apoio financeiro.

\section{REFERÊNCIAS BIBLIOGRÁFICAS}

1. Pihlajaniemi V, Sipponen S, Sipponen MH, Pastinen O, Laakso S. Enzymatic saccharification of pretreated wheat straw: Comparison of solids-recycling, sequential hydrolysis and batch hydrolysis. Bioresour. Technol. 2014 Feb; 153: 15-22, doi: 10.1016/j.biortech.2013.11.060.

2. Dagnino EP, Chamorro ER, Romano SD, Felissia FE. Area MC. Optimization of the acid pretreatment of rice hulls to obtain fermentable sugars for bioethanol production. Ind. Crops Prod. 2013 Mar; 42: 363-8, doi: 10.1016/j.indcrop.2012.06.019.

3. Georgieva TI, Ahring BK. Evaluation of continuous ethanol fermentation of dilute-acid corn stover hydrolysate using thermophilic anaerobic bacterium Thermoanaerobacter BG1L1. Appl. Microbiol. Biotechnol. 2007 Nov; 77(1): 61-8, doi: 10.1007/s00253-007-1149-8.

4. Matos EHSF. Dossiê técnico cultivo do milho verde. CDT - Centro de Apoio ao Desenvolvimento Técnico, Brasília, UNB; 2007. 24 p.

5. Ritchie SW, Hanway JJ, Benson GO. Como a planta de milho se desenvolve. Arquivo Agrônomo, $\mathrm{n}^{\circ}$ 15, 2003. 20p. (Informações Agronômicas, n.103 - setembro/2003).

6. Food and Agriculture Organization of the United Nations - FAO [citado em 28 de setembro de 2016]. Disponível em http://faostat3.fao.org.

7. Companhia Nacional de Abastecimento, CONAB 2016. Acompanhamento da Safra Brasileira de Grãos. [atualizado em 10 de agosto de 2016; citado em 28 de setembro de 2016]. Disponível em: http://www.conab.gov.br/OlalaCMS/uploads/arquivos/16_08_09_12_08_19_boletim_graos _agosto_20 16.pdf.

8. Santos MSR. Estudo de pré - tratamentos de palha e sabugo de milho visando a produção de etanol 2G. [dissertação]. Maceió-AL (Brasil): Universidade Federal de Alagoas; 2014. 75 p.

9. Torre P, Aliakbarian B, Rivas B, Domínguez JM, Converti A. Release of ferulic acid from corn cobs by alkaline hydrolysis. Biochem. Eng. J. 2008 Jul; 40 (3): 500-6, doi: 10.1016/j.bej.2008.02.005.

10. Tsai WT, Chang CY, Wang SY, Chang CF, Chien SF, Sun HF. Preparation of activated carbons from corn cob catalyzed by potassium salts and subsequent gasification. Bioresour. Technol. 2001 Jun; 78 (2): 203-8, doi: 10.1016/S0960-8524(00)00111-5.

11. Horst DJ. Avaliação da produção energética a partir de ligninas contidas em biomassas. [dissertação]. Ponta Grossa - PR (Brasil): Universidade Tecnológica Federal do Paraná; 2013. 103 p.

12. Kim TH, Kim TH. Overview of technical barriers and implementation of cellulosic ethanol in the U.S. Energy. 2014 Mar; 66: 13-9, doi: 10.1016/j.energy.2013.08.008

13. Kato DM, Elía N, Flythe M, Lynn BC. Pretreatment of lignocellulosic biomass using Fenton chemistry. Bioresour. Technol. 2014 Jun; 162: 273-8, doi: 10.1016/j.biortech.2014.03.151.

14. Maurya DP, Singla A, Negi S. An overview of key pretreatment processes for biological conversion of lignocellulosic biomass to bioethanol. Biotech. 2015 Feb; 5: 597-609, doi: 10.1007/s13205-015-0279-4.

15. Sun Y, Cheng J. Hydrolysis of lignocellulosic materials for ethanol production: a review. Bioresour. Technol. 2002 May; 83 (1):1-11, doi: 10.1016/S0960-8524(01)00212-7.

16. Behera S, Arora R, Nandhagopal N, Kumar S. Importance of chemical pretreatment for bioconversion of lignocellulosic biomass. Renew. Sust. Energ. Rev. 2014 May; 36: 91-106, doi: 10.1016/j.rser.2014.04.047.

17. Silva GM. Pré-tratamento do bagaço de cana de açúcar com amônia aquosa para a produção de etanol. [dissertação]. São Carlos - SP (Brasil): Universidade Federal de São Carlos, 2011. 125 p.

18. Balat M, Balat H, Cahide O. Progress in bioethanol processing. Prog. Energ. Combust. Sci. 2008 Oct; 34 (5): 551-73, doi: 10.1016/j.pecs.2007.11.001. 
19.Dae Sung Kim, Aye Aye Myint, Hun Wook Lee, Junho Yoon, Youn-Woo Lee. Evaluation of hot compressed water pretreatment and enzymatic saccharification of tulip tree sawdust using severity factors. Bioresour. Technol. 2013 Sep; 144: 460-6, doi: 10.1016/j.biortech.2013.06.071.

20. Petersen MO, Larsen J, Thomsen MH. Optimization of hydrothermal pretreatment of wheat straw or production of bioethanol at low water consumption without addition of chemicals. Biomass Bioenerg. 2009 May; 33 (5): 834-40, doi: 10.1016/j.biombioe.2009.01.004.

21. Abdullah R, Ueda K, Saka S. Hydrothermal decomposition of various crystalline celluloses as treated by semi-flow hot-compressed water. J. Wood Sci. 2014 Aug; 60 (4): 278-86, doi:10.1007/s10086014-1401-7.

22. Xiao LP, Shi ZJ, Xu F, Sun RC. Hydrothermal treatment and enzymatic hydrolysis of Tamarix ramosissima: Evaluation of the process as a conversion method in a biorefinery concept. Bioresour. Technol. 2013 May; 135: 73-81. doi:10.1016/j.biortech.2012.08.143.

23. Pereira SC, Maehara L, Machado CMM, Farinas CS. Physical-chemical-morphological characterization of the whole sugarcane lignocellulosic biomass used for $2 \mathrm{G}$ ethanol production by spectroscopy and microscopy techniques. Renew. Energ. 2016 Mar; 87(1): 607-17, doi: 10.1016/j.renene.2015.10.054.

24. Gouveia ER, Nascimento RT, Souto-Maior AM. Validação de metodologia para a caracterização química de bagaço de cana-de-açúcar. Quim. Nova 2009 Jul; 32 (6): 1500-3.

25. Nakasu PYS. Cinética da hidrólise ácida do licor obtido após pré-tratamento hidrotérmico. [dissertação]. Campinas - SP (Brasil): Universidade Estadual de Campinas; 2015. 176 p.

26. Silva GM. Avaliação de diferentes configurações de hidrólise enzimática e fermentação utilizando bagaço de cana-de-açúcar para a produção de etanol 2G. [tese]. São Carlos - SP (Brasil): Universidade Federal de são Carlos; 2015. 142p.

27. Santos-Rocha MSR, Pratto B, Sousa Júnior R, Almeida RMRG, Cruz AJG. A kinetic model for hydrothermal pretreatment of sugarcane straw. Bioresour. Technol. 2016 Mar; 228: 176-5, doi: 10.1016/j.biortech.2016.12.087.

28. Silva GM, Giordano RLC, Cruz AJG, Ramachandriya KD, Banat IM, Wilkins MR. Ethanol production from sugarcane bagasse using ssf process and thermotolerant yeast. ASABE. 58(2): 193200, doi: 10.13031/trans.58.11024.

29. Silva VFN, Arruda PV, Felipe MGA, Gonçalves AR, Rocha GJM. Fermentation of cellulosic hydrolysates obtained by enzymatic saccharification of sugarcane bagasse pretreated by hydrothermal processing. J. Ind. Microbiol. Biot. 2011 Jul; 38 (7): 809-17, doi: 10.1007/s10295-010-0815-5.

30. Overend RP, Chornet E, Gascoigne JA. Fractionation of lignocellulosics by steam-aqueous pretreatments. Philos. T. R. Soc. A.1987 Apr; 321 (1561): 523-36, doi: 10.1098/rsta.1987.0029.

31. Sluiter A, Hames B, Ruiz R, Scarlata C, Sluiter J, Templeton D, Crocker D. Determination of structural carbohydrates and lignin in biomass. Technical Report NREL/TP-510-42618. 2008. 18 p.

32. Rocha G, Silva F, Curvelo A, Araújo G. A fast and accurate method for determination of cellulose and polyoses by HPLC. Fifth Brazilian Symp. Chem. lignins other wood components. 1997. 6 p.

33. Cotta JAO, Salami FH, Marques AR, Rezende MOO, Landgraf MD. Validação do método para determinação de nitrogênio Kjeldahl total. Revista analytica. 2007 Jan; 26: 68-75.

34. Miller GL. Use of dinitrosalicylic acid reagent for determination of reducing sugar. Anal. Chem. 1959 Mar, 31 (3): 426-8, doi: 10.1021/ac60147a030.

35. Abud AKS. Estudo do comportamento cinético e da estabilidade de uma linhagem recombinante de Saccharomyces cerevisiae no processo de fermentação alcóolica de amiláceos. [dissertação]. São Paulo (Brasil): Universidade de São Paulo. 1997.

36. Nogueira AMP, Venturini-Filho WG. Aguardente de cana. Botucatu: Faculdade de Ciências Agronômicas, Brasil, 2005, $1 \mathrm{v}$.

37. Ramachandriya KD, Wilkins M, Pardo-Planas O, Atiyeh HK, Dunford NT, Hiziroglu S. Simultaneous saccharification and fermentation of eastern red cedar heartwood and sapwood using a novel size reduction technique. Bioresour. Technol. 2014 Jun; 161: 1-9, doi: 10.1016/j.biortech.2014.03.005.

38. Santos FA, Queiróz JH, Colodette JL, Manfredi M, Queiroz MELR, Caldas CS, Soares FEF. Otimização do pré-tratamento hidrotérmico da palha de cana-de-açúcar visando à produção de etanol celulósico. Quim. Nova. 2014; 37 (1): 56-62, doi: 10.1590/S0100-40422014000100011.

39. Martínez JDA. Modelagem cinética da hidrólise enzimática da palha de cana-de-açúcar pré-tratada hidrotermicamente. [dissertação]. Rio de Janeiro (Brasil): Universidade Federal do Rio de Janeiro; 2014. $107 \mathrm{p}$.

40. Oliveira LRM, Nascimento VM, Gonçalves AR, Rocha GJM. Combined process system for the production of bioethanol from sugarcane straw. Ind. Crops Prod. 2014 Jul; 58: 1-7, doi: 10.1016/j.indcrop.2014.03.037. 
41. Kim DS, Myint AA, Lee HW, Yonn J, Lee YW. Evaluation of hot compressed water pretreatment and enzymatic saccharification of tulip tree sawdust using severity factors. Bioresour. Technol. 2013 Sep; 144: 460-6, doi: 10.1016/j.biortech.2013.06.071.

42. Garrote G, Domínguez H, Parajó JC. Autohydrolysis of corncob: Study of non-isothermal operation for xylooligosaccharide production. J. Food Eng. 2002 May; 52 (3): 211-8, doi:10.1016/S02608774(01)00108-X.

43. Boussarsar H, Rogé B, Mathlouthi M. Optimization of sugarcane bagasse conversion by hydrothermal treatment for the recovery of xylose. Bioresour. Technol. 2009 Dec; 100 (24): 6537-42, doi: 10.1016/j.biortech.2009.07.019.

44. Mittal A, Chatterjee SG, Scott GM, Amidon TE. Modeling xylan solubilization during autohydrolysis of sugar maple wood meal: Reaction kinetics. Holzforschung. 2009 Jan; 63: 307-14, doi:10.1515/HF.2009.054.

45. Santucci BS, Maziero P, Rabelo SC, Curvelo AAS, Pimenta MTB. Autohydrolysis of Hemicelluloses from Sugarcane Bagasse During Hydrothermal Pretreatment: a Kinetic Assessment. Bioenerg. Res. 2015 Dec; 8 (4): 1778-87. doi:10.1007/s12155-015-9632-z.

46. Kim TH. Bioconversion of Lignocellulosic Material into Ethanol: pretreatment, enzyme hydrolysis, and ethanol fermentation. [dissertation]. Auburn-AL (EUA): Auburn University; 2004. 187 p.

47. Wolf LD. Pré-tratamento organossolve do bagaço de cana-deaçúcar para a produção de etanol e obtenção de xilooligômeros. [dissertação]. São Carlos - SP (Brasil): Universidade Federal de São Carlos; 2011. 148 p.

48. Accellerase ${ }^{\circledR} 1500$. Cellulase enzyme complex for lignocellulosic biomass hydrolysis. Du Pont. [citado em 28 de setembro de 2016]. Disponível em http://accellerase.dupont.com/fileadmin /user_upload/live/accellerase/documents/DUP-00413_ProdSheet_1500_web.pdf. 